\title{
Ludic strategy for promoting engagement of parents and caregivers in the safety of pediatric patients
}

\author{
Estratégia lúdica para promoção do engajamento de pais e \\ acompanhantes na segurança do paciente pediátrico \\ Estrategia lúdica para promover el compromiso de padres y \\ acompañantes en la seguridad del paciente pediátrico
}

\section{Karyne Maria de Morais Gonçalves ${ }^{a}$ Maria Tereza Teles Coelho Aguiar Costa ${ }^{a}$ Débora Caixeta Bernardes Silva ${ }^{a}$ Manuela Estrela Baggio ${ }^{b}$ Allana dos Reis Corrêab Bruna Figueiredo Manzoc}

\section{How to cite this article:} Gonçalves KMM, Costa MTTCA, Silva DCB, Baggio ME, Corrêa AR, Manzo BF. Ludic strategy for promoting engagement of parents and caregivers in the safety of pediatric patients. Rev Gaúcha Enferm. 2020;41:e20190473. doi: https://doi. org/10.1590/1983-1447.2020.20190473
Universidade Federal de Minas Gerais (UFMG), Escola de Enfermagem. Belo Horizonte, Minas Gerais, Brasil.

' Universidade Federal de Minas Gerais (UFMG), Escola de Enfermagem, Departamento de Enfermagem Básica. Belo Horizonte, Minas Gerais, Brasil.

Universidade Federal de Minas Gerais (UFMG), Escola de Enfermagem, Departamento de Enfermagem Materno-Infantil e Saúde Pública. Belo Horizonte, Minas Gerais, Brasil.

\section{ABSTRACT}

Objective: To evaluate a ludic strategy developed to promote the engagement of parents and caregivers in the pediatric patient safety actions.

Method: A qualitative research developed in the action-research modality, using the thematic content analysis method for data treatment, developed with caregivers of children admitted to the pediatric unit of the public hospital of Belo Horizonte, Minas Gerais, between May and October 2018.

Results: Three thematic categories emerged: Learning about patient safety through the game; Game evaluation as a ludic strategy in promoting patient safety and; Change of perception and behavior of parents and caregivers in safety promotion actions.

Conclusion: The game was deemed as an important tool for patient safety knowledge transfer, motivating parents and caregivers to become more critical and more co-participant as for the hospitalized child care.

Keywords: Games, experimental. Pediatric nursing. Patient safety. Patient participation. Child, hospitalized.

\section{RESUMO}

Objetivo: Avaliar uma estratégia lúdica desenvolvida para promover 0 engajamento dos pais e acompanhantes nas ações de segurança do paciente pediátrico.

Método: Pesquisa qualitativa na modalidade de pesquisa-ação, utilizando a análise de conteúdo temática para tratamento dos dados. Desenvolvida com acompanhantes das crianças internadas na pediatria de um hospital público de Belo Horizonte, Minas Gerais, entre maio e outubro de 2018. A coleta ocorreu em duas fases: ação (estratégia lúdica) e exploratória (avaliação do conhecimento). Resultados: Emergiram três categorias temáticas: Aprendendo sobre segurança do paciente por meio do jogo; Avaliação do jogo como estratégia lúdica na promoção da segurança do paciente; e Mudança de percepção e comportamento dos pais e acompanhantes nas ações de promoção da segurança.

Conclusão: 0 jogo apresentou-se como importante ferramenta de transferência de conhecimento sobre segurança do paciente, motivando os pais e acompanhantes a se tornarem críticos e coparticipantes quanto à assistência à criança hospitalizada.

Palavras-chave: Jogos experimentais. Enfermagem pediátrica. Segurança do paciente. Participação do paciente. Criança hospitalizada.

\section{RESUMEN}

Objetivo: Evaluar una estrategia lúdica desarrollada para promover la participación de padres y acompañantes en acciones de seguridad de pacientes pediátricos.

Método: Investigación cualitativa llevada a cabo bajo la modalidad de investigación de acción, utilizando el método de análisis de contenido temático para el tratamiento de datos, desarrollado con cuidadores de niños ingresados a la unidad de pediatría del hospital público de Belo Horizonte, Minas Gerais, entre mayo y octubre de 2018.

Resultados: Surgieron tres categorías temáticas: Aprender sobre la seguridad del paciente a través del juego; La evaluación del juego como estrategia lúdica para promover la seguridad del paciente y; Cambio de percepción y comportamiento de padres y cuidadores en acciones de promoción de seguridad.

Conclusión: El juego se presentó como una herramienta importante para la transferencia de conocimiento sobre la seguridad del paciente, y para motivar a los padres y cuidadores a ser más críticos con respecto al cuidado de los niños hospitalizados y a desempeñar su rol como copartícipes en la prevención de incidentes.

Palabras clave: Juegos experimentales. Enfermería pediátrica. Seguridad del paciente. Participación del paciente. Niño hospitalizado. 


\section{口INTRODUCTION}

Patient safety is becoming increasingly relevant in the world scenario as one of the pillars of health care quality, being related to a set of actions that aims to reduce unnecessary harms associated with health care to an acceptable minimum $^{(12)}$. Potential risks for the patient are intrinsic to care complexity, especially for children in critical conditions, due to physical and psychological characteristics, which can considerably influence patient safety ${ }^{(1-2)}$.

The breach of safety can imply exposure to adverse events, which results in longer hospital stays, increased costs and morbidity and mortality rates ${ }^{(3)}$. An American study carried out in pediatric hospitals used the Global Trigger Tool developed by the Institute of Healthcare Improvement $(I H I)$ and analyzed 600 medical records, identifying 240 adverse events. Of these, 108 were potentially avoidable, the most common being related to intravascular catheters, respiratory assistance, surgical complications, and skin lesions ${ }^{(4)}$.

To contribute to the prevention of adverse events, the World Health Organization (WHO) instituted the "Patients for Patient Safety Program" aiming at the active participation of citizens in their safety, with a view to improving health care and controlling incidents ${ }^{(2)}$. In the case of pediatric inpatient units, parents and caregivers are involved in this action, as patients are often unable to contribute to the control of their own safety.

In this setting, it is essential to encourage the effective participation of the caregiver in the care of hospitalized children, so that they become barriers to prevent adverse events. When they are heard and instructed to participate actively in care and treatment, they are no longer passive recipients of health care and become partners in preventing harms, contributing to safer care $e^{(5)}$. In this sense, the authors warn on the need for health institutions to encourage the exchange of knowledge among the patients, caregivers and professionals, so that the culture of patient safety is disseminated and care is built based on the partnership among all the involved people(6).

Studies with an emphasis on patient safety and family participation emphasize that caregivers can act as barriers at any stage of the care process, especially those works linked to communication and information of caregivers, in the practice of invasive procedures and participation of the caregiver in the care provided. This becomes possible when there is active listening and partnership between the professionals and the caregivers for the child's comfort and safety ${ }^{(5,7)}$.

Although patient and caregiver engagement is viewed positively for patient safety, there is insufficient evidence on strategies that seek to overcome barriers that interfere with the willingness of these caregivers to become co-participants in care, as proposed by the National Patient Safety Program (Programa Nacional de Segurança do Paciente, PNSP) ${ }^{(5)}$.

In this context, a ludic strategy was developed and implemented, by means of a game, which aimed to empower parents and caregivers and encourage them to participate in the safety of hospitalized children. Given the aforementioned, the following guiding question arose: How can a ludic strategy promote the engagement of parents and caregivers in pediatric patient safety actions?

It is believed that the findings may contribute to the evaluation and improvement of the intervention with parents and caregivers in the search for greater safety during hospitalization. Thus, this study aimed to assess a ludic strategy developed to promote the engagement of parents and caregivers in pediatric patient safety actions.

\section{METHOD}

This is a qualitative research developed in the form of action-research, which aims to investigate and intervene favorably in the face of a certain problem and, as a result, produce new knowledge. This type of research also provides for the planning and execution of educational actions/ programs; development and testing of educational tools, methodological and assessment strategies; and creating new learning environments; among others ${ }^{(8)}$.

A total of 17 parents and caregivers of children admitted to the pediatric unit of a public hospital in Belo Horizonte, Minas Gerais, participated in the game and in the interviews. This sector has 37 beds and serves children from 1 month to 16 years old and with clinical and surgical conditions. The occupancy of this unit is around $90 \%$ to $100 \%$, with a mean length of stay of 10 to 15 days. The institution was chosen for participating in some Ministry of Health projects in the field of patient safety, seeking strategies that encourage caregivers and parents to be co-participants in the care of hospitalized children.

Data collection was developed in two phases, action and exploratory, between May and October 2018. The inclusion criteria were the following: parents or caregivers of children hospitalized for more than 48 hours in the pediatric unit and who participated in the ludic intervention. The participants who interrupted the proposed activity at some point were excluded.

In the action phase, the research consisted of a board game developed by the researchers, which included 20 question sheets with the objective of reflecting on the knowledge 
and actions to promote the engagement of parents and caregivers in patient safety. The guiding items of the discussions originated from the handbook of the National Health Surveillance Agency called "How can I contribute to increase patient safety?", which includes the following themes: patient identification; preventing health-related infection through hand hygiene; preventing medication errors; preventing pressure and fall injuries; safety in surgery; and effective communication ${ }^{(5)}$. For each question, there was only one correct answer, and the other three alternatives consisted of incorrect information, but usually seen in scenes of patient care. As an example, the moderator asked when the patients must have their bracelets checked by the health care professional. The answers were the following: a) [correct] Upon admission, before performing a procedure, and on discharge of the patients; b) Only when the patients arrive at the hospital. c) At the beginning and end of each professional's work shift; d) After performing the procedure. (Figure 1)

The game sessions took place in the wards, lasting approximately 20 to 30 minutes, with the participation of two to six players, who were parents or caregivers; and, when older than 6 years old, the children were part of the group, together with their guardian. For being an interactive game, the presence of a trained mediator was important in conducting the intervention in order to mediate the questions and answers, provide an exchange of experience between the players, offer an explanation in the practice, and clarify questions about the topic.
During the game, it was possible to notice that the parents and caregivers felt the need to disclose some situation of almost error or error experienced in the unit and to report the feelings generated under the circumstance. Thus, the situation and actions that could have been taken in order to avoid adverse events were discussed.

The exploratory and evaluation phase took place two days after the participation of the parents and caregivers in the game. This time was important so that the participants could have the opportunity to use the information acquired during the care of the children. All the participants in the first stage were invited to answer an interview with a semi-structured script, held individually in a reserved location, conducted by two previously trained researchers and recorded with prior authorization. Its duration ranged from 15 to 20 minutes.

The interview script consisted of questions that referred to the evaluation of the game as a strategy for engaging parents and caregivers in the safety culture, such as: "How do you perceive your knowledge and your commitment to promoting safety before and after participating in the game? Report an experience that caught your attention after participating in the game. What suggestions would you give regarding the game in the search for its improvement?"

The number of interviews was determined by means of data saturation, that is, suspension of inclusion of new participants when no new elements are found ${ }^{(9)}$. It is highlighted that there was no dropout or loss during data collection.
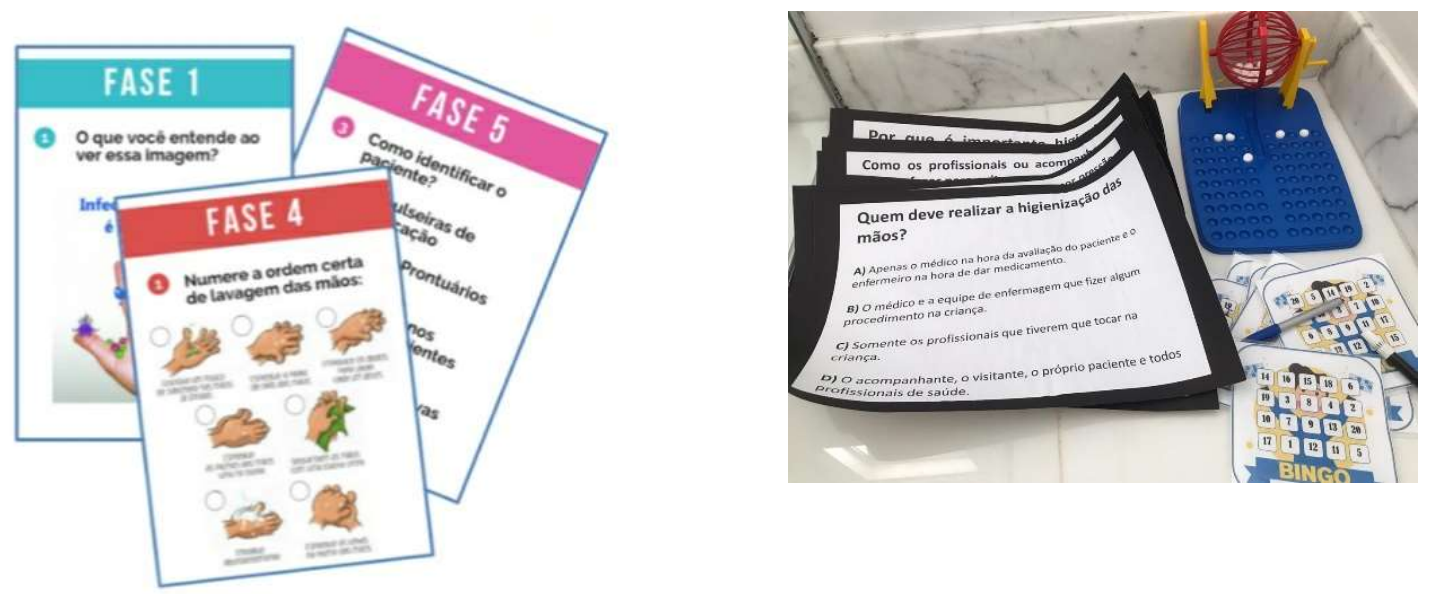

Figure 1 - Illustration on the components of the game designed for the action phase of the study Source: The authors. 
To maintain anonymity, the reports of each interviewee are encoded by the letter E for interviewee ("Entrevistado" in Portuguese), followed by a numerical number to represent the order of participation, from 1 to 17, for example, E1 for Interviewee 1.

The interview data were transcribed in full by the researchers and analyzed according to the content analysis method (thematic category), according to pre-analysis, material exploration, and treatment of the results ${ }^{(9)}$. Three thematic units emerged, which were interpreted and discussed, correlating the themes with the theoretical framework on the subject; thereafter, the contents were transformed into meaningful and valid information ${ }^{(7)}$.

It is highlighted that this study complied with the ethical aspects recommended by Resolution No. 466/2012, of the National Health Council, which establishes guidelines and ethical standards for the study involving human beings, with the approval of the Research Ethics Committee Involving Human Beings of the proposing institution, under opinion No.2,895,491 and CAAE: 96623218.9.0000.5149. The participants signed the Free and Informed Consent Form (FICF) before the study started.

\section{Q RESULTS}

The participants were predominantly women and mothers, aged between 19 and 45 years old, and most of them with complete high school. The process of qualitative data analysis originated three thematic categories: Learning about patient safety; Evaluating the game as a ludic strategy in promoting patient safety; and Change of perception and behavior of parents and caregivers in actions to promote safety after participation in the game.

\section{Learning about patient safety through the game}

When the interviewees were asked about patient safety, it was noticed that most of them could not conceptualize it in an integral way, but described it by means of examples in the practical context, such as: identifying the patients correctly; improving drug safety; and reducing both the risk of health care-associated infections and the risk of falls for the patient.

Patient safety is their proper identification in the hospital, being identified on the bed plate, on the bracelet that they usually also use, so that at the time they get some drug they can be identified. This identification, I understand as safety identification, so that there are really no errors. (E6)
[...] washing your hands when you mess with the child, having to wash your hands when you enter and pass an alcohol. (E11)

Patient safety is to lift the bar so as not to fall, avoid letting run. (E13)

I think it would be to be aware of the issue of medication, verify if the medical diagnosis is corresponding for avoiding any medical error. Also, staying tuned when they are in bed, not leaving them alone, and avoiding these things. (E1)

It was observed that the caregivers perceived their responsibility in the search for patient safety, acting as a barrier to preventing adverse events:

Patient safety, I understand as a measure that both people who deal with the patient and the caregiver have to take [...] to make sure they are okay, that nothing hinders their recovery. (E5)

It is necessary that all the mothers be more attentive with the medications, the care of their babies, because even so they can get confused with the name, so as not to miss any medication. (E4)

We can be a barrier [...] asking to be able to carry out sanitation. (E14)

It means taking all the cares, always keeping at the patient's side, the headboard elevated, and the bars elevated, all for the patient's well-being. (E16)

\section{Evaluating the game as a ludic strategy in promoting patient safety}

The participants evaluated the use of the game as an enlightening, informative, and educational resource, which shows simple language and a relaxed approach on the topic:

[...] there's always something you don't know and the opportunity to clarify the doubt in the game. For example: Washing the hands with alcohol or with water? When do I do this? So, for sure, it changed and added. If I played the game again, I'd add even more things. (E5)

[...] I found it really cool, because it clarifies for us some things that we don't know as a caregiver, like for example, that we have the right to ask and receive explanations about everything that is happening. [...] the toy for me reinforced everything that happened, because he [son] is also aware of what is happening. (E8) 
It was a good experience, it made melearn more. Understanding things / didn't know and ending up learning. (E9)

(...) it was very fun. I liked it, the children liked it, and everybody was interacting a lot. "(...) it was a very good learning, a ludic way that I always recommend and find very cool. (E15)

(...) it was very good. (...) I had difficulty expressing myself, I was able to express myself better with the game, it's easier. (E17)

The interview reports confirmed the benefits of integrating playfulness with patient safety. They evidenced the use of the game as a facilitator of the process of coping with hospitalization.

Interesting, because the child is playing, distracting, building new connections and seeing the hospital with another face (...). (E10)

It was good, very relaxed for us. (...) it was very cool that we have fun and learn [...]. And in the form of a game, being able to learn more and know more. (E6)

Many interviewees highlighted the importance of the child's active participation in the game, which, in their perception, promoted children's responsibility, autonomy, and involvement in the context of safety actions.

It was interesting to see them participating and interacting [...]. (E2)

What impressed me the most was seeing [...] (my daughter) talking with authority, as if she knew a lot. (E6)

[...] they participate and understand how it works [...]. They know that they have to identify themselves, [...] the risks they run or not during hospitalization, they know the medications. (E8)

She likes it, she's learning, because she has... then... a difficulty to learn things, and it's good to encourage her, I think it's better. (E12)

The participants evaluated the game as an innovative strategy, which aims to raise awareness and exchange information between family members and professionals about actions that favor patient safety. They also suggested expanding its dissemination to other areas, in addition to Pediatrics.

I'd like you to expand to everyone. Especially for children, because with children the treatment is different. The adult has a resistance, a very different view of things, and the child does not. And your work strengthens their knowledge. (E8)

Very interesting, constructive, different. I hadn't seen anything like that in the hospital before, but yes in the school. (E10)

\section{Change of perception and behavior of parents and caregivers in actions to promote safety after participation in the game}

In the interviewees'statements, it was evident that, after having experienced the game, they were more critical and attentive to the care provided by the multi-professional team.

Before the game, it was zero, which we don't know how it works and, after the game, we start to understand a little bit. [...] we do everything intuitively before the game. (E8) It changed a lot, because before I didn't have the knowledge that I helped the nurses by asking them what medication they're applying to the child, the medication schedule. Through us, they know if they're applying the right medication, if they aren't at the right time. It's quite rewarding! (E7)

[...] it taught me to wash my hand right, I didn't know I had to do that much of maneuver. When I go to wash my hand, I remember the game. (E14)

The change in behavior and the motivation to participate in decisions involving the care of children were evident in the statements.

I think that sometimes, some nurses have to pay more attention to what they do. Just like yesterday, if it wasn't for the other nurse, she would've turned off my girl's access. And if she had removed the serum access, the access would've been lost. (E14)

[...] today / saw that the doctor came and already touched the patient without first sanitizing herself. I already saw that in her, usually we don't stop to watch. (E2)

[...] I was even more attentive to myself... how to wash my hands daily, with the professionals, if they're washing properly, I watch a lot if they're drinking alcohol before evaluating the child. With the medication too, I always ask what medication is and they explain to me right. (E4) It changed, because now if I go out, I raise the crib bar so that he doesn't fall; when I let it down, I stay close so that he doesn't fall. And there are also the medication hours: I know how many hours, what he takes, why he takes. (E11) 


\section{DISCUSSION}

The findings of this study corroborate the results of other researchers when they report that the patients and caregivers characterize patient safety by exemplifying actions $^{(1,10)}$.

The parents and caregivers recognized their own importance in the search for patient safety, acting as barriers to prevent adverse events. This idea is similar to that of a study carried out in Portugal, which found the importance of caregivers in monitoring the care offered by the professionals and in the safety culture ${ }^{(11)}$. The literature suggests that, when involved as an active partner in the care process, the caregiver can assist in the early detection of accidents, as in the observation of the medication performed, correct identification of the patient ${ }^{(1)}$.

Still, in line with the findings of this study on family participation in the prevention of adverse events; another study conducted in a pediatric hospital identified that patients and family members alerted the health professionals against medication errors in $15 \%$ of the cases, with many of these errors associated with possible harms. The presence of the well-oriented family possibly contributed to awareness raising regarding the safety actions ${ }^{(12)}$. Informed and empowered patients act efficiently and help in the search for better results and fewer incidents. Thus, the guideline is for them to be informed and aware of the health situation and of safety issues, as well as to have their doubts clarified ${ }^{(13)}$.

The reports indicate that, after the caregivers were instructed by means of the game, they felt safer and motivated to act in the child's care and, consequently, in the promotion of patient safety. In line with this note, a Swedish study showed that, when patients receive well-structured information from the multi-professional team, they are able to be more efficiently involved in patient safety actions. The educational intervention provided information and clarification to the patients and caregivers on the activities developed by the health, treatment, and care teams, allowing them to detect possible errors and breaches of patient safety barriers ${ }^{(14)}$.

Using the game showed potential for the development of the co-participation of the caregivers in relation to the care of the child. Confirming this finding, a number of studies showed that the ludic intervention allows for reflection, for the construction of critical thinking, and for the interaction between the participants and the professionals, in addition to becoming an encouraging factor for behavioral changes ${ }^{(15-16)}$.
A research study carried out in a pediatric unit in Brazil showed that the mothers feel calmer when experiencing playfulness with their children, who showed signs of distraction, overcoming, and understanding regarding hospitalization. This finding also converges with the data from the present study, which confirm the benefits of using the game as a facilitator in the process of coping with hospitalization and as an information vehicle ${ }^{(17)}$.

The participation of the patients becomes a strategy to improve safety and to ensure care centered on them, being considered an essential element for developing quality in care. The international policy developed by the WHO highlights the increasing involvement of patients and family members in the health services, acting on the strategies in the search for safety ${ }^{(10)}$. Other authors also highlight that the patient and the caregiver play a crucial role in providing information, since they are a constant presence in all the transition times of the team ${ }^{(18)}$. In this context, the authors note that patient involvement is a shared responsibility between the health team and the patient/family, and that the health professional is responsible for creating opportunities for patient participation ${ }^{(14)}$.

Interventions that aim to improve the activation and promotion of positive patient habits are gaining prominence in the international literature, in addition to being a requirement for safe practices in the health services. According to the Patient Health Engagement (PHE) model, the patients' engagement involves their ability to create realistic life plans, turning them into actors of their life decisions, by means of a participatory approach to the management of their health and care actions ${ }^{(19)}$. It is worth highlighting that this engagement is not always a linear path, in addition to presenting different forms of interaction between the health service and the patient, according to the phase of the process they are going through ${ }^{(19)}$.

The participants reported that, after the game, they felt more confident in questioning the professionals and alerting them against something they were unaware of. In this sense, the authors emphasize that the empowerment of the patient and the caregiver in care is considered a strategy for reducing incidents, so that they are able to interact and contribute to obtaining best practices in health care ${ }^{(13,20)}$. In 2018, the Speak Up ${ }^{\text {TM }}$ About Your Care campaign was reactivated, which has the purpose of educating patients and caregivers to adopt practices, such as Speak: talking and questioning about the treatment; Pay attention: paying attention to the care actions received; Educate yourself: educating oneself about one's own health condition, not feeling overwhelmed when questioning the professionals; 
Advocates can help: including family, friends, and caregivers as partners in understanding health care actions; Know about your new medicine: obtaining information and questioning about the medications received; Use a quality health care organization: using health services that adhere to the patient safety practices; Participate in all decisions about your care: participating in all treatment decisions, strengthening relationships with the health team ${ }^{(20)}$.

It is highlighted that using the game in this study sought to promote the engagement of the parents and caregivers in patient safety actions, which does not mean transferring the responsibility for patient safety from the professional to the caregiver. What needs to happen is co-responsibility of the care. In this sense, the authors emphasize that, in order to build the care plan for hospitalized children, it is necessary to create a partnership and to consider all the knowledge and experiences of the family and the child, in order to provide safe and holistic care focused on the patient's needs ${ }^{(10-11)}$.

As a limitation to the application of the game, this research presented the restriction of the physical space available in the pediatric inpatient unit. However, this situation did not preclude the implementation of the ludic strategy, since the researchers used the spaces of the wards for its execution.

\section{CONCLUSION}

The findings evidenced the game as an educational, instructional, and ludic tool with regard to the patient safety. The participants reported that, after the ludic strategy, they started to observe, intervene, and actively participate in the care provided by the health professionals to the hospitalized children, becoming more critical and empowered. They also recognized the importance of their participation linked to the multi-professional team, with regard to the actions to promote patient safety and prevent incidents in the pediatric unit.

The study consists of an innovative work aimed at promoting knowledge and engagement of the parents and caregivers in patient safety, as well as it indicates the need for new studies to discuss the strategies for promoting greater knowledge and engagement of the parents and caregivers in the safety actions of the hospitalized children. Furthermore, it is expected that discussions about the participation of caregivers in preventing adverse events and in developing the institutional safety culture will be incorporated into the training process of the health professionals, in the care and management scenario.

\section{REFERENCES}

1. Peres MA, Wegner W, Cantarelli-Kantorski KJ, Gerhardt LM, Magalhães AMM. Perception of family members and caregivers regarding patient safety in pediatric inpatient units. Rev Gaúcha Enferm. 2018;39:e2017-0195. doi: https://doi.org/10.1590/1983-1447.2018.2017-0195

2. Ministério da Saúde (BR, Fundação Oswaldo Cruz, Agência Nacional de Vigilância Sanitária. Documento de referência para o Programa Nacional de Segurança do Paciente. Brasília, DF: Ministério da Saúde; 2014 [cited 2019 Oct 10]. Available from: http://bvsms.saude.gov.br/bvs/publicacoes/documento_ referencia_programa_nacional_seguranca.pdf

3. Lanzillotti LS, Seta MH, Andrade CL, Mendes JuniorWV. Adverse events and other incidents in neonatal intensive care units. Ciênc Saúde Coletiva. 2015;20(3):93746. doi: https://doi.org/10.1590/1413-81232015203.16912013

4. Stockwell DC, Bisarya $H$, Classen DC, Kirkendall ES, Landrigan CP, Lemon V, et al. A trigger tool to detect harm in pediatric inpatient settings. Pediatrics. 2015;135(6):1036-42. doi: https://doi.org/10.1542/peds.2014-2152

5. Agência Nacional de Vigilância Sanitária (BR). Pacientes pela segurança do paciente em serviços de saúde: como posso contribuir para aumentar a segurança do paciente? orientações aos pacientes, familiares e acompanhantes. Brasília: Anvisa; 2017 [cited 2019 Oct 10]. Available from: http://portal.anvisa.gov.br/documents/33852/3507912/Como+posso+ contribuir+para+aumentar+a +seguran\%C3\%A7a+do+paciente/52ef bd76-b692-4b0e-8b70-6567e532a716

6. Hoffmann LM, Wegner W, Biasibetti, Peres MA, Gerhardt LM, Breigeiron MK. Patient safety incidents identified by the caregivers of hospitalized children. Rev Bras Enferm. 2019;72(3):707-14. doi: https://doi. org/10.1590/0034-7167-2018-0484

7. Silva EMB, Pedrosa DLL, de Leça APC, Silva DM. Health professionals'perceptions of pediatric patient journal safety culture. Rev Enf Ref. 2016;4(9):87-95. doi: https://doi.org/10.12707/RIV16007

8. Toledo RF, Giatti LL, Jacobi PR. Action research in interdisciplinary studies: analysis on criteria that can be revealed only through practice. Interface (Botucatu). 2014; 18(51):633-46. doi: https://doi.org/10.1590/1807-57622014.0026

9. Richardson RJ. Pesquisa social: métodos e técnicas. São Paulo: Atlas; 2017.

10. Ringdal M, Chaboyer W, Ulin K, Bucknall T, Oxelmark L. Patient preferences for participation in patient care and safety activities in hospitals. BMC Nurs. 2017;16:69. doi: https://doi.org/10.1186/s12912-017-0266-7

11. Melo EMOP, Ferreira PL, Lima RAG, Mello DF. The involvement of parents in the healthcare provided to hospitalzed children. Rev Latino-Am Enfermagem. 2014;22(3):432-9. doi: https://doi.org/10.1590/0104-1169.3308.2434

12. Manias E, Cranswick N, Newall F, Rosenfeld E, Weiner C, Williams A, et al. Medication error trends and effects of person-related, environment-related and communication-related factors on medication errors in a paediatric hospital. J Paediatr Child Health. 2018;55(3):320-6. doi: https://doi.org/10.1111/ jpc. 14193

13. Silva TRG, Manzo BF, Fioreti FCCF, Silva PM. Family-centered care from the perspectiveofnursesintheNeonatallntensiveCareUnit.RevRene.2016;17(5):64350. doi: https://doi.org/10.15253/2175-6783.2016000500009

14. Skagerström J, Ericsson C, Nilsen P, Ekstedt M, Schildmeijer K. Patient involvement for improved patient safety: a qualitative study of nurses' perceptions and experiences. Nurs Open. 2017; 4(4):230-9. doi: https://doi. org/10.1002/nop2.89 
15. Fernandes CS, Martins MM, Gomes BP, Gomes JA, Gonçalves LHT. Family Nursing Game: developing a board game. Esc Anna Nery. 2016;20(1):33-7. doi: https://doi.org/10.5935/1414-8145.20160005

16. Fernandes CS, Angelo M, Martins MM. Giving Voice to Caregivers: a game for family caregivers of dependent individuals. Rev Esc Enferm. USP. 2018;52:e03309. doi: https://doi.org/10.1590/ S1980-220X2017013903309

17. Fioreti FCCF, Manzo BF, Regino AEF. The play therapy and child hospitalized in perspective of parents. REME. 2016;20:e974. doi: http://www.dx.doi. org/10.5935/1415-2762.20160044

18. Manias E, Bucknall T, Hughes C, Jorm C, Woodward-Kron R. Family involvement in managing medications of older patients across transitions of care: a systematic review. BMC Geriatrics. 2019;19:95. doi: https://doi.org/10.1186/ s12877-019-1102-6

\section{- Corresponding author:}

Bruna Figueiredo Manzo

E-mail: brunaaamancio@yahoo.com.br
19. Graffigna G, Barello S. Spotlight on the Patient Health Engagement model (PHE model): a psychosocial theory to understand people's meaningful engagement in their own health care. Patient Prefer Adherence. 2018;12:1261-71. doi: https://doi.org/10.2147/PPA.S145646

20. The Joint Commission (US) [Internet]. Oakbrook, IL; The Commission; c201802020 [cited 2019 0ct 10]. Speak up ${ }^{\text {TM. }}$. About your care; [about 1 screen]. Available from: https://www.jointcommission.org/resources/for-consumers/ speak-up-campaigns/about-your-care/

\section{Funding:}

Hospital Foundation of the State of Minas Gerais (Fundação Hospitalar do Estado de Minas Gerais, FAPEMIG). Edict No. 001/2017.

\section{Associate editor:}

Wiliam Wegner 